\section{Is there a differential in the dental health of new recruits to the British Armed Forces? A pilot study}

\author{
T. B. Elmer, ${ }^{1}$ J. Langford, ${ }^{2}$ R. McCormick ${ }^{3}$ and A. J. Morris ${ }^{4}$
}

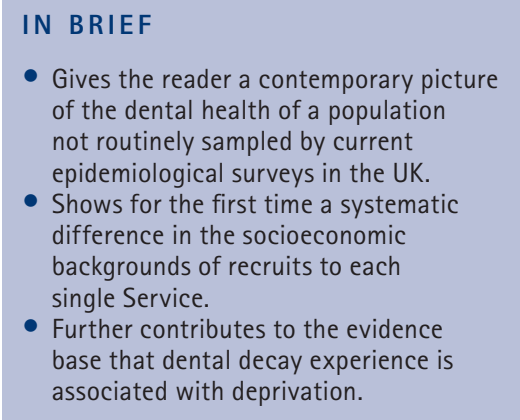

\begin{abstract}
Background and aim Figures from the British Defence Dental Services reveal that serving personnel in the British Army have a persistently lower level of dental fitness than those in the Royal Navy or the Royal Air Force. No research had been undertaken to ascertain if this reflects the oral health of recruits joining each Service. This study aimed to pilot a process for collecting dental and sociodemographic data from new recruits to each Service and examine the null hypothesis that no differences in dental health existed. Method Diagnostic criteria were developed, a sample size calculated and data collected at the initial training establishments of each Service. Results Data for 432 participants were entered into the analysis. Recruits in the Army sample had a significantly greater prevalence of dental decay and greater treatment resource need than either of the other two Services. Army recruits had a mean number of $2.59(2.08,3.09)$ decayed teeth per recruit, compared to $1.93(1.49,2.39 p<0.01)$ in Royal Navy recruits and $1.26(0.98,1.53 p<0.001)$ in Royal Air Force recruits. Among Army recruits 62.7\% were from the two most deprived quintiles of the Index of Multiple Deprivation compared to 42.5\% of Royal Naval recruits and 36.6\% of Royal Air Force recruits. Conclusion A significant difference in dental health between recruits to each Service does exist and is a likely to be a reflection of the sociodemographic background from which they are drawn.
\end{abstract}

\section{INTRODUCTION}

Despite the fall of the Berlin Wall and the end of the Cold War, evolving theatres of conflict around the globe continue to see the UK's Armed Forces operating at a consistently high tempo.

The vast majority of UK Service personnel have good access to primary dental care while not deployed on operations. ${ }^{1}$ However, a significant proportion of the Armed Forces are in environments which do not allow them easy access to this facility.

In February 2011 there were approximately 9,000 UK Service personnel from all three Services deployed in Afghanistan,

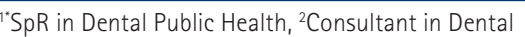
Public Health, West Midlands Strategic Health Authority, St Chad's Court, 213 Hagley Road, Birmingham, B16 9RG; ${ }^{3}$ Late/Royal Army Dental Corps, Defence Consultant Adviser in Dental Public Health, HO Joint Medical Command, DMS Whittington, Lichfield, WS19 4PY; ${ }^{4}$ Consultant in Dental Public Health, South Staffordshire Primary Care Trust, Anglesey House, Rugeley, WS15 1UL

*Correspondence to: Surg Cdr (D) Timothy B. Elmer RN Email: tim.elmer@southstaffspct.nhs.uk
}

Online article number E18

Refereed Paper - accepted 24 August 201

DOI: $10.1038 /$ sj.bdj.2011.937

${ }^{\circledR}$ British Dental Journal 2011; 211: E18 with the majority being from the Army. Many of these personnel are geographically detached from the available intheatre dental support and as a result, for an individual experiencing dental pain, accessing dental services may mean travel by road or air across hostile terrain with commensurate risks.

In reporting dental morbidity in the UK Armed Forces in Iraq 2003, ${ }^{2}$ Richardson estimated that the overall dental morbidity rate was between 148 cases per 1,000 personnel per year (Royal Navy) and 160 cases per 1,000 personnel per year (Army). Additional reports for Service personnel deployed to Iraq $^{3,4}$ and Bosnia ${ }^{5}$ have reported attendance rates for emergency dental care between 121 and 185 attendances per 1,000 personnel per year while a survey of unscheduled attendances for dental problems in Royal Naval ${ }^{6}$ ships reported 52 such occurrences per 1,000 personnel per year. Some specific military employment groups such as aircrew or divers may also experience barodontalgia or barotrauma ${ }^{7,8}$ through operating in specific environments.
In a review of the literature on dental casualty rates in different nationality forces deployed worldwide, Mahoney ${ }^{9}$ concluded that during a conflict the expected rate of dental emergencies would be between 150-200 per 1,000 personnel per year, and that overall 10-15\% of the force would become a dental casualty. On this basis, the expected total number of dental casualties for UK Forces in Afghanistan would be between 1,350-1,800 per year, or as many as five per day.

Dental pain leading to sleep deprivation or an inability to eat can degrade the morale of an individual, rendering him or her less militarily effective.

All Services have a key role to play and it follows that each should, from a dental health perspective, be equally well prepared. Dental fitness in the British Armed Forces is expressed as the percentage of personnel in the 'trained strength' (ie excluding recruits) who have had all their treatment needs met. Between March 2005 and March 2010 this figure remained stable for the Royal Navy and Royal Air Force at approximately $75 \%$ while for the same 
period the Army figure varied between $50 \%$ and $60 \%$.

This suggests some dental health inequalities exist between the three Services, with an apparent and persistent unmet need in the Army. There is evidence that higher states of dental fitness result in lower numbers of dental casualties ${ }^{10-12}$ and it would therefore appear that Army personnel are at greater risk of becoming dental casualties during a period of operational intensity when they can least afford to be so.

What is unclear is whether this inequality is present when recruits join the Armed Forces, or if a combination of prevalence of dental decay, enforced mobility, access, deployment or levels of dental service provision affects the ability of each Service to render its personnel dentally fit. The aim of this paper was to pilot a process whereby dental data for recruits to the Army, Royal Navy or Royal Air Force could be simultaneously collected with a view to testing the null hypothesis that no difference in dental health existed between them.

\section{METHODS}

A cross sectional study design was used to capture information from a sample of recruits entering each of the Services during 2010. Diagnostic criteria were developed, drawing on elements from those used in the UK Adult Dental Health Survey ${ }^{13}$ as well as by Richardson and Macintyre ${ }^{14}$ but with the critical difference that the findings of contemporary bitewing radiographs were included as these form part of the initial dental assessment of all new recruits.

Data collected included age, gender, smoking status, decayed, missing and filled teeth (DMFT) and the individual fractions of D, M, and F. Only teeth with dental decay that, in the opinion of the clinical examiner, required intervention were recorded as decayed. This criterion reflects the pragmatic nature of the study and identifies the downstream treatment resource requirement.

In addition to the Basic Periodontal Examination (BPE) score, the number of teeth the examiners assessed as requiring endodontic treatment or extraction due to dental disease were recorded, as well as the total treatment resource need expressed in units of 0.5 dental man hours and the home postcode of each participant.
The clinical information was retained for six weeks before being analysed as most recruits who are discharged or withdraw voluntarily do so during this period. Those who left or were discharged were excluded from the analysis.

The locations identified for data collection were the initial entry training establishments for each of the Services. The single sites serving the Navy and Air Force see all recruits irrespective of gender or future employment group. The Army has five sites, some of which process single sex recruit groups for specific employment. For this pilot, Pirbright garrison near Woking in Surrey was chosen for the Army recruits as it processes recruits of both sexes from different career employment groups.

A sample size calculation was performed and, after making an allowance for recruits who did not complete training and forms which were lost, damaged or illegible, 130 forms were distributed to each initial entry training centre.

Clinical examinations were carried out in similarly equipped surgeries with similar light sources. All recruits over the age of 17 passing through the selected initial entry training establishments between 1 March and 31 May 2010 were eligible for inclusion in the study.

Two examiners from each establishment underwent a training and calibration process on the dental health components of the data set described in the diagnostic criteria. A Cohen Kappa score of 0.8 was calculated using a statistical software package (STATA 11, StataCorp, 4905 Lakeway Drive, College Station, Texas 77845 USA) suggesting a strong degree of agreement between all examiners.

\section{Data analysis and statistical methods}

Much of the dental data collected had a strong positive skew. The Kruskal-Wallis test $(\mathrm{KW})$ was used to identify any significant differences between the three Services overall and the Mann-Whitney U test was used to identify differences between individual Service pairings (Army-Navy; Army-RAF; Navy-RAF). The p-value for significance was adjusted to 0.017 to compensate for multiple hypothesis testing (Bonferroni correction).

Postcode data was used to derive the Index of Multiple Deprivation (IMD) quintiles for England, Northern Ireland, Scotland and Wales from which each recruit originated. IMD quintile 1 represents the most deprived and quintile 5 the least.

\section{RESULTS}

In total, 457 forms were returned, 160 from the Army, 170 from the Navy and 127 from the Air Force. For two of the Services, this represents a greater number of forms than were originally distributed and reflected the size of recruit intake at that time. Data collection was complete except for postcode, where $11 \%$ of recruits either did not know their postcode or else gave one that did not match with any database. The overall rate of withdrawal from training was much lower than expected which, in combination with the number of forms returned, resulted in a much larger sample size than anticipated, giving a more precise sample estimate.

Median age in the sample as a whole was 20 years (IQR 17-24). 92.8\% of the overall sample were male, while the proportion of smokers was slightly higher than the national average ${ }^{15}$ for the age group 17-34, with $29.5 . \%$ of men and $28.1 \%$ of women being smokers.

The postcode data was used to estimate UK country of origin for most recruits, although this in no way inferred ethnicity. The majority of recruits came from England (77\%), with progressively smaller numbers from Scotland (6\%), Wales (4\%) and Northern/Southern Ireland (1\%) respectively.

A significant proportion of Army recruits were from the two most deprived quintiles of IMD, with $62.7 \%$ of their intake coming from quintiles 1 and 2. The Royal Navy displayed no apparent pattern of recruitment from any particular quintile while the Royal Air Force had a slight trend for recruiting from the less deprived quintiles, with 42.2\% coming from quintiles 4 and 5 and only 36.6\% from quintiles 1 and 2.

When decayed, missing or filled teeth or the requirement for extraction was cross tabulated with IMD quintile, there was a strong association for increasing prevalence of decayed, missing or filled teeth or the need for extraction with decreasing quintile of IMD. No recruits from IMD quintile 5 in any Service required endodontic treatment.

The KW test showed there were significant differences between Services in 


\begin{tabular}{|c|c|c|c|c|c|}
\hline $\begin{array}{l}\text { Mean number of decayed } \\
\text { teeth per recruit overall }\end{array}$ & n (recruits) & Mean & SD & Std error & $95 \% \mathrm{Cl}$ \\
\hline Army & 147 & 2.59 & 3.10 & 0.25 & $2.08,3.09$ \\
\hline Royal Navy & 162 & 1.93 & 2.86 & 0.22 & $1.49,2.39$ \\
\hline Air Force & 123 & 1.26 & 1.56 & 0.14 & $0.98,1.53$ \\
\hline \multicolumn{6}{|c|}{ KW test: decayed: chi-squared with ties $=14.135$ with 2 d.f. $p<0.001$} \\
\hline $\begin{array}{l}\text { Mean number of decayed } \\
\text { teeth per recruit when } \\
\text { decayed }>0\end{array}$ & n (recruits) & Mean & SD & Std error & $96 \% \mathrm{Cl}$ \\
\hline Army & 104 & 3.60 & 3.11 & 0,31 & $3.06,4.27$ \\
\hline Royal Navy & 90 & 3.48 & 3.06 & 0.32 & $2.84,4.12$ \\
\hline Air Force & 69 & 2.25 & 1.44 & 0.17 & $1.89,2.59$ \\
\hline
\end{tabular}

Table 2 Mean number of $\mathbf{3 0}$ minute appointments needed per recruit overall and when treatment need $>0$ by Service

\begin{tabular}{l|l|l|l|l|l|}
\hline $\begin{array}{l}\text { Treatment need per } \\
\text { recruit in 30 minute units }\end{array}$ & $\mathrm{n}$ & $\begin{array}{l}\text { Mean no. of } \\
\text { appointments }\end{array}$ & SD & Std error & $95 \% \mathrm{Cl}$ \\
\hline Army & 147 & 2.42 & 2.64 & 0.22 & $1.98,2.84$ \\
\hline Royal Navy & 162 & 1.73 & 2.76 & 0.22 & $1.30,2.15$ \\
\hline Air Force & 123 & 1.28 & 1.75 & 0.16 & $0.96,1.59$ \\
\hline
\end{tabular}

KW test: treatment need: chi-squared with ties $=17.799$ with 2 d.f. $p<0.001$

\begin{tabular}{l|l|l|l|l|l}
$\begin{array}{l}\text { Treatment need in } 30 \\
\text { minute units for recruits } \\
\text { whose treatment need }>0\end{array}$ & $\mathrm{n}$ & $\begin{array}{l}\text { Mean no. of } \\
\text { appointments }\end{array}$ & SD & Std error & $95 \% \mathrm{Cl}$ \\
\hline Army & 106 & 3.35 & 2.56 & 0.25 & $2.86,3.85$ \\
\hline Royal Navy & 92 & 3.04 & 3.07 & 0.32 & $2.41,3.68$ \\
\hline Air Force & 78 & 2.01 & 1.83 & 0.21 & $1.60,2.42$ \\
\hline
\end{tabular}

KW test: treatment need $>0$ : chi-squared with ties $=19.963$ with 2 d.f. $p<0.001$

the mean number of decayed teeth per recruit $(\mathrm{p}<0.001)$ and treatment resource requirement ( $\mathrm{p}<0.001)$. The mean number of decayed teeth per recruit was highest in the Army sample $(2.59 ; 2.08-3.09)$ and lowest in the Royal Air Force (1.26; 0.98-1.53), with the Royal Navy having a mean of 1.93 (1.49-2.39). This relationship was maintained when the mean number of decayed teeth in those personnel with any dental decay (decayed $>0$ ) was examined ( $\mathrm{p}<0.05)$ (Table 1).

Overall, 72.1\% (n = 106) of Army recruits, 63.5\% $(\mathrm{n}=78)$ of RAF recruits and 56.8\% ( $\mathrm{n}=92)$ of Navy recruits were assessed as needing some treatment (Table 2). Army recruits required on average nearly twice the amount of treatment resource time as recruits to the Royal Air Force.
The results of the Mann-Whitney U tests on the possible Service pairings are shown in Table 3. Army recruits had a significantly greater prevalence of overall dental decay and treatment need compared to the other two Services as well as having a greater need for extractions. In recruits where decayed $>0$, there was a significant difference between Army and Royal Air Force recruits, but not between Army and Royal Navy.

It would appear that the Army, which recruits most heavily from the most deprived IMD quintiles, is more likely to encounter recruits with a greater prevalence of dental decay and commensurately higher levels of treatment need.

\section{DISCUSSION}

There were some limitations to this pilot study:
The examiners performing the data collection were not blinded to the rationale behind the study. This introduced the theoretical possibility of bias in data collection by examiners selecting recruits with the highest levels of dental disease for inclusion in the study rather than in sequence as instructed.

Each country has its own IMD; these are conceptually similar and share some common domains, but are calculated using different indicators, weightings and geographies. The IMD quintiles used have been based on the broad assumption that sociodemographically there is equivalence in relative deprivation by quintile irrespective of country.

The use of Pirbright garrison alone rather than sampling from all Army training establishments may have introduced some bias. Work is ongoing to repeat the methodology piloted in other Army initial training establishments to assess if there are intra-Service differences between these centres. Early analysis of data from Catterick garrison (all male, all infantry) suggests that the sociodemographic profile is similar to the Pirbright sample but with an even greater prevalence of dental decay and treatment need. As nearly half of the Army's recruits pass through Catterick, these results may reinforce the findings of this study and highlight the gap in dental health between recruits to the Army and the other two Services.

It appears that there is a dental health inequality among recruits to the different Services which in turn appears to be a reflection of the social backgrounds from which the recruits are drawn. The relationship between dental disease and deprivation is well established ${ }^{16}$ but on the basis of this sample, it would appear that by delivering up to 2 hours of treatment, $85 \%$ of Army recruits, $90 \%$ of Naval recruits and $97 \%$ of RAF recruits could be rendered 'dentally fit' by Service standards. This mirrors the findings of Hurley and Tuck $^{17}$ and highlights the principles that underpinned the terms of project Military Oral Liability Army Recruits (M.O.L.A.R), introduced by the Army in 2006. Under the terms of M.O.L.A.R, each Army recruit is allocated 2 hours time for dental treatment during their initial entry training.

There are several questions which remain unanswered, foremost among which is 


\begin{tabular}{|c|c|c|c|}
\hline Variable & Service pairing & z-score & $\mathrm{p}$-value \\
\hline \multirow[t]{3}{*}{ Overall number of decayed teeth } & Army v Navy & 2.69 & 0.007 \\
\hline & Army $\vee$ RAF & 3.65 & $<0.001$ \\
\hline & Navy $\vee$ RAF & 0.85 & 0.39 \\
\hline \multirow{3}{*}{$\begin{array}{l}\text { Number of decayed teeth when } \\
\text { decayed teeth }>0\end{array}$} & Army v Navy & 0.61 & 0.54 \\
\hline & Army $\vee$ RAF & 2.98 & 0.003 \\
\hline & Navy $\vee$ RAF & 2.21 & 0.027 \\
\hline \multirow{3}{*}{$\begin{array}{l}\text { Overall number of teeth needing } \\
\text { extraction }\end{array}$} & Army v Navy & 4.27 & $<0.001$ \\
\hline & Army v RAF & 3.21 & 0.001 \\
\hline & Navy v RAF & -0.84 & 0.399 \\
\hline \multirow[t]{3}{*}{ BPE score } & Army v Navy & 1.00 & 0.316 \\
\hline & Army $\vee$ RAF & -2.35 & 0.019 \\
\hline & Navy $\vee$ RAF & -3.15 & 0.002 \\
\hline \multirow[t]{3}{*}{ Overall treatment need } & Army v Navy & 3.46 & $<0.001$ \\
\hline & Army $\vee$ RAF & 3.83 & $<0.001$ \\
\hline & Navy $\vee$ RAF & -0.04 & 0.97 \\
\hline \multirow[t]{3}{*}{ Treatment need when need $>0$} & Army v Navy & 2.06 & 0.039 \\
\hline & Army $\vee$ RAF & 4.61 & $<0.001$ \\
\hline & Navy v RAF & 2.10 & 0.035 \\
\hline \multirow[t]{3}{*}{ Index of Multiple Deprivation quintile } & Army v Navy & -3.71 & $<0.001$ \\
\hline & Army v RAF & -3.80 & $<0.001$ \\
\hline & Navy v RAF & -0.72 & 0.474 \\
\hline
\end{tabular}

why this inequality persists year on year after recruits have left training and become regular members of the Army.

The results from this study show there is a great deal of disease in a small proportion of the population, and for the $15 \%$ of Army recruits who cannot be made fit within 2 hours, they may represent a cumulative burden of high need patients entering the trained strength of the Army. Research by York et al. ${ }^{18}$ showed that in a cohort of recruits to the US Armed Forces, for those who joined in 'Dental Readiness Classification 3' (urgent dental treatment required, dental conditions likely to result in a dental emergency within 12 months), only 57.4\% were ever made dentally fit during the 4 years following entry. While the M.O.L.A.R. model is horizontally equitable, it may have disadvantaged some of those with the greatest need. Further research is needed into the barriers to accessing dental care for Army personnel both during training and after joining the trained strength. rejected as a difference does exist, and that difference is largely due to the greater prevalence of dental decay and higher treatment need in the Army over its two sister Services; this in turn is a reflection of the sociodemographic background from which Army recruits are drawn. In order to better inform the planning of future dental services, further research is needed into factors affecting access to dental care within the Army and to assess if differentials exist in dental health between recruits at individual Army training establishments.

I am indebted to the staff of each initial entry training establishment and to Surg Cdr (D) S. Howe RN, Surg Lt (D) M. Bamber RN, Ms N. Benson, Col S. Gamble RADC, Maj N. Gibbs RADC, SSgt T. Lambert RADC, Wg Cdr S. Doyle $R A F$ and Sgt A. Jackson RAF for their help and assistance in performing the clinical examinations and collecting the data.

1. Personal correspondence between author and Defence Dental Services Headquarters regarding achievement of access KPI's.

2. Richardson PS. Dental morbidity in United Kingdom armed forces, Iraq 2003. Mil Med 2005; 170: 536-541.

3. Dunn W J, Langsten R E, Flores S, Fandell J E. Dental emergency rates at two expeditionary medical support facilities supporting operations Enduring and Iraqi Freedom. Mil Med 2004; 169: 510-514.

4. Deutsch W M, Simecek J W. Dental emergencies among marines ashore in Operations Desert Shield/ Storm. Mil Med 1996; 161: 620-623.

5. Chaffin J, King J E, Fretwell L D. U S Army dental emergency rates in Bosnia. Mil Med 2001; 166: 1074-1078.

6. Alexander D C. Dental recall status and unscheduled dental attendances in British warships. Mil Med 1996; 161: 268-272.

As the distribution of dental disease in recruits to the Armed Forces is a reflection of dental disease in society at large, the ongoing collective efforts of the NHS to reduce population oral health inequalities through oral health promotion, water fluoridation and the commissioning of appropriate dental services in more deprived areas may offer the greatest chance of addressing any inequality by improving the dental health of personnel before they join the Forces. There is also great latitude to extend the sociodemographic profiling in assessing differences in general health occurring between the Services as part of a broader public health orientated approach.

\section{CONCLUSION}

On the basis of these findings the null hypothesis that there is no difference in the dental health of recruits entering each of the three Services can be
7. Zadik Y. Aviation dentistry: current concepts and practice. Br Dent J 2009; 206: 11-16.

8. Al-Hajri W, Al-Madi E. Prevalence of barodontalgia among pilots and divers in Saudi Arabia and Kuwait. Saudi Dent J 2006; 18: 134-140.

9. Mahoney D. A literature review of dental casualty rates. Mil Med 2000; 165: 751-756.

10. Simecek J W. Estimation of nonpreventable dental emergencies in U S Marine Corps personnel. Mil Med 2008; 173: 1104-1107.

11. Skec V, Macan D, Spicek J, Susac M, Luksic I. Influence of oral health on combat readiness in the Croatian Army. Mil Med 2002; 167: 1016-1019.

12. Richardson PS. Dental risk assessment for military personnel. Mil Med 2005; 170: 542-545.

13. Office for National Statistics. Adult dental health survey. Oral health in the United Kingdom 1998. Appendix C. London: The Stationery Office, 1999.

14. Richardson PS, McIntyre I G. Dental treatment needs of a cohort of Royal Air Force recruits over 5 years. Community Dent Health 1996; 13: 11-16.

15. Robinson S, Lader D. Smoking and drinking among adults 2010. In General household survey 2007. London: Office for National Statistics, 2008.

16. Locker D. Deprivation and oral health: a review. Community Dent Oral Epidemiol 2000; 28: 161-169.

17. Hurley S J, Tuck J. Improving the dental fitness of the British Army by changing the strategy for dental care provision for recruits from a vertically equitable model to a horizontally equitable model. Mil Med 2007; 172: 1182-1185.

18. York A K, Moss D L, Martin G. A longitudinal study of dental experience during the first four years of military experience. Mil Med 2008; 173(Suppl 1): 38-41. 